\title{
Police Legitimacy and the Norm to Cooperate: Using a Mixed Effects Location-Scale Model to Estimate the Strength of Social Norms at a Small Spatial Scale
}

\author{
Jonathan Jackson ${ }^{1,2}$ (D) lan Brunton-Smith ${ }^{3}$ - Ben Bradford ${ }^{4} \cdot$ Thiago R. Oliveira $^{1}$. \\ Krisztián Pósch ${ }^{4} \cdot$ Patrick Sturgis ${ }^{1}$
}

(C) The Author(s) 2020

\begin{abstract}
Objectives Test whether cooperation with the police can be modelled as a place-based norm that varies in strength from one neighborhood to the next. Estimate whether perceived police legitimacy predicts an individual's willingness to cooperate in weak-norm neighborhoods, but not in strong-norm neighborhoods where most people are either willing or unwilling to cooperate, irrespective of their perceptions of police legitimacy.

Methods A survey of 1057 individuals in 98 relatively high-crime English neighborhoods defined at a small spatial scale measured (a) willingness to cooperate using a hypothetical crime vignette and (b) legitimacy using indicators of normative alignment between police and citizen values. A mixed-effects, location-scale model estimated the cluster-level mean and cluster-level variance of willingness to cooperate as a neighborhood-level latent variable. A cross-level interaction tested whether legitimacy predicts individual-level willingness to cooperate only in neighborhoods where the norm is weak.

Results Willingness to cooperate clustered strongly by neighborhood. There were neighborhoods with (1) high mean and low variance, (2) high mean and high variance, (3) (relatively) low mean and low variance, and (4) (relatively) low mean and high variance. Legitimacy was only a positive predictor of cooperation in neighborhoods that had a (relatively) low mean and high variance. There was little variance left to explain in neighborhoods where the norm was strong.

Conclusions Findings support a boundary condition of procedural justice theory: namely, that cooperation can be modelled as a place-based norm that varies in strength from neighborhood to neighborhood and that legitimacy only predicts an individual's willingness to cooperate in neighborhoods where the norm is relatively weak.
\end{abstract}

Keywords Police $\cdot$ Legitimacy $\cdot$ Cooperation $\cdot$ Micro-place $\cdot$ Multi-level modelling

Electronic supplementary material The online version of this article (https://doi.org/10.1007/s1094 0-020-09467-5) contains supplementary material, which is available to authorized users.

Jonathan Jackson

j.p.jackson@1se.ac.uk

Extended author information available on the last page of the article 


\section{Introduction}

Security cannot be produced by either police or citizens acting alone. Legal authorities rely on the public to report crimes, provide intelligence and give evidence in court, and it is important to put into place policies and practice in ways that secure active public support if the police, criminal courts and correctional facilities are to effectively fight crime and maintain social order. Procedural justice theory (PJT; Tyler and Huo 2002; Tyler and Fagan 2008) is a popular account of police-citizen relations aimed at understanding what police officers can do to encourage public cooperation and legal compliance. In this paper we use an innovative statistical tool - the mixed-effects, location-scale model (Hedeker et al. 2008; Leckie et al. 2014; Brunton-Smith et al. 2018) — to examine an as-yet unexplored boundary condition of PJT: namely, that legitimacy only plays a role when the norm to cooperate is weak in an individual's own neighborhood.

PJT is premised on the idea that there are normative motivations to cooperate with the police (e.g. the public belief that the police have a valid claim to power and are therefore entitled to be obeyed) and there are instrumental motivations to cooperate (e.g. the public balancing of the risks and benefits of proactive support) and that each is associated with a different style of policing (Sunshine and Tyler 2003; Tyler 2006a, b; Tyler and Trinkner 2018). On the one hand, an instrumental account of cooperation stresses a more coercive style of policing, whereby officers encourage cooperative behaviour by wielding their authority in ways that signal effectiveness, protection, strength and power. On the other hand, a normative account of cooperation stresses consensual social control practicesofficers encourage proactive public support by acting in ways that signal respect, neutrality, accountability and moral authority.

Tests in the US, UK and Australia generally find that perceived police legitimacy is a more important predictor of cooperation than instrumental factors related to effectiveness and risk (Tyler 2006a, b, 2013; Huq et al. 2011; Jackson et al. 2013a; Tyler and Jackson 2014; Murphy et al. 2015, 2017; Madon et al. 2016; Bolger and Walters 2019). Work from an increasing number of countries across the world has also addressed the factors that legitimate the police (Jackson 2018). Overall, the available evidence suggests that police need to act in procedurally just ways if they want to generate popular legitimacy, increase public cooperation, and thereby fight crime (President's Task Force on 21st Century Policing 2015).

There is also empirical support for the role that neighborhood context plays in people's willingness to cooperate with the police (Kochel 2018a, b; Berg et al. 2013; Gau et al. 2012; Slocum et al. 2010; Warner 2007; Goudriaan et al. 2006). In their assessment of contextual factors that are separate from police activity, many of these studies have tested whether structural and/or social neighborhood characteristics help explain the clustering of levels of public cooperation from one locality to the next. For example, Jackson et al. (2013a) found (a) that public willingness to cooperate with the police in London was clustered by neighborhood, (b) that neighborhood levels of collective efficacy, disorder and fear of crime explained this clustering, not crime, deprivation, residential stability and ethnicity diversity, and (c) that legitimacy played an important individual-level role in motivating cooperation and mediating some of the statistical effects of neighborhood context on cooperation. The argument was that public cooperation and police legitimacy are both rooted in whether the local area seems to successfully police itself, with poor social conditions linked to beliefs among local residents that police 
power is not justified, that their authority is open to question, and therefore that cooperation with them should be avoided.

In this paper we contribute to the criminological literature on police legitimacy and public willingness to cooperate with the police. Focusing on the individual and the neighbourhood level, we consider the idea that living in a neighborhood in which there is a strong shared social norm to cooperate has an important place-based effect on an individual's own personal willingness to cooperate with the police. Social norms are standards or expectations of behaviour that are based on shared beliefs that guide and/ or constrain social behaviour among members of a social group. One reason why people may (or may not) be willing to cooperate with the police is-we argue-that they have (or have not) internalised the social norm that they should be willing to proactively help the police fight crime; cooperating is what people should do and cooperating is what other people would expect them to do. Moreover, we posit that these place-based norms operate at a small spatial scale. In neighborhoods with a widely shared social norm to cooperate, residents (1) generally believe that it is appropriate to conform to this expectation (i.e. are willing to cooperate with the police if the need and/or opportunity arose), (2) believe that others in the neighborhood also believe this, (3) expect others in the neighborhood to conform (and disapprove of those who do not), which implies that (4) an individual living in such a neighborhood is more willing to cooperate because she believes that others expect her to also conform and will censure her in some way if she does not.

To assess this neighborhood-level account of public willingness to cooperate with the police, we draw on data from a survey of individuals living in neighborhoods within a large metropolitan area of England. We define neighborhoods at a small spatial scale, and we fit a mixed-effects, location-scale model (Hedeker et al. 2008; Leckie et al. 2014; Brunton-Smith et al. 2018) to estimate the neighborhood-level mean and variance of residents' expressed willingness to cooperate with the police. This analytical strategy allows us to more adequately assess the strength of spatially-varying social norms compared to standard mixed effects models. Our approach addresses the question of whether some localities have a strong normative consensus of cooperation with the police, other neighborhoods exhibit a strong norm not to cooperate, and still other neighborhoods exhibit relatively weak normative pressure.

We also assess an under-explored boundary condition in PJT: namely, that legitimacy only plays a role when the norm to cooperate is weak in an individual's neighborhood. A norm is strong in a social group when most members of the group have internalized it, and in the context of place-based norms to cooperate, this may mean that local residents will (irrespective of their perceptions of police legitimacy) be willing to cooperate because most people in their neighborhood believe that they would-and should-help the police if the situation were to arise and that others would disapprove if they did not cooperate. Conversely, in the context of placed-based norms not to cooperate, most people in the neighborhood (irrespective of their perceived police legitimacy) believe that they would not-and should not-help the police if the situation were to arise and that others would disapprove if they did cooperate. If the social norm to cooperate dominates in a locality then cooperation is taken as given; nearly everyone is willing to cooperate so there is no space for legitimacy to play a role. But in neighborhoods where the norm is weak, legitimacy provides an incentive to cooperate with an institution when it is considered to be moral, just and appropriate.

From a methodological perspective, our study contributes to the criminological literature by applying a new statistical model for estimating the social characteristics of 
neighborhoods. A large and growing body of work has applied multi-level modelling to address questions about, inter alia, legal cynicism, collective efficacy and police legitimacy within neighborhoods (Sampson et al. 1997; Sampson and Bartusch 1998; Kirk and Papachristos 2011; Jackson et al. 2013a). A development of this framework-the mixedeffects location scale model-allows us to model within-neighborhood heterogeneity in the norm to cooperate as a function of characteristics of neighborhoods and individuals. We also assess whether this heterogeneity in norm strength across neighborhoods can explain variability in the relationship between police legitimacy and willingness to cooperate.

The remainder of the paper proceeds as follows. First, we review the literature on what motivates people to be willing to pro-actively cooperate with the police. After documenting relevant ethnographic work that drove-and helps us illustrate-our intuition, we motivate the current theoretical expectation: namely, that cooperation is a placed-based norm that is stronger in some neighborhoods than others, and that residents of strong norm localities will be willing to cooperate, independently of their perception of police legitimacy. Second, we present the analytical strategy. We explain why we use an innovative sampling design (detailed below) and why we fit a novel statistical model (the mixed effects locationscale model) to estimate the cluster-level mean and variance. Third, we outline our data and methods. Fourth, we present the results. The final section considers the implications of our findings, how they might be taken forward in later work, and what the mixed-effects location-scale model adds to the methodological toolbox for criminologists interested in modelling social characteristics of neighborhood.

\section{Why Do People Cooperate with the Police?}

The police rely on the public working with them to effectively manage crime. It is important to have robust evidence on what legal authorities can do to encourage public support. Thus far, there is a good deal of empirical support for key predictions of procedural justice theory, particularly the role that perceived police legitimacy plays in explaining variation in people's willingness to cooperate with the police (President's Task Force on 21st Century Policing 2015). For example, Sunshine and Tyler (2003) found that New York City residents who viewed the police as legitimate also tended to report a willingness to cooperate. Tyler and Fagan's (2008) longitudinal study found something similar. In both cases, the instrumental motivations against which legitimacy was compared were public assessments of police performance in fighting crime and perceived risk of being caught for low-level criminal behavior. In related work, White et al. (2016) found that individuals (who had been arrested for a variety of different crimes in Arizona) who felt a normatively grounded sense of support for-and deference toward-the police also tended to report being willing to report a crime to the police. This was true for each offender type, e.g., violent, property, or drug crime. In Mazerolle et al.'s (2013) randomized controlled trial of process-based policing in Queensland, Australia, legitimacy (similarly measured) was found to be a strong predictor of willingness to cooperate with the police. Bolger and Walters (2019) carried out a meta-analysis of the effect of beliefs about the legitimacy of the police on people's willingness to cooperate, finding an average positive effect and evidence of heterogeneity in the strength of the relationship between police legitimacy and willingness to cooperate.

What is legitimacy? At the conceptual level, Tyler (2006a, b, 375) defines legitimacy as: '... a psychological property of an authority, institution, or social arrangement that leads 
those connected to it to believe that it is appropriate, proper, and just. Because of legitimacy, people feel that they ought to defer to decisions and rules, following them voluntarily out of obligation rather than out of fear of punishment or anticipation of reward.' At the operational level, researchers have measured legitimacy in a variety of different ways (for discussion, see Reisig et al. 2007; Hawdon 2008; Bottoms and Tankebe 2012; Tyler and Jackson 2013; Jackson and Gau 2015; Hamm et al. 2017; Jackson 2018; Jackson and Bradford 2019; Trinkner 2019; Posch et al. forthcoming). One approach has been to use a single indicator of trust or confidence in the police as a proxy for legitimacy (e.g. Boateng 2017). A second approach has been to treat legitimacy as unidimensional using a scale of obligation to obey, a scale of institutional trust, or by combining obligation to obey and institutional trust (e.g. Mazerolle et al. 2013). A third approach has been to measure legitimacy along two dimensions: judgements of appropriateness and entitlement, with studies differentiating between either (1) obligation to obey and institutional trust (e.g. Reisig et al. 2007) or (2) obligation to obey and normative alignment (e.g. Huq et al. 2017). This approach is premised on defining legitimacy along two connected lines: (a) normative justifiability of power in the eyes of citizens (the right to power) and (b) recognition of rightful authority (the authority to govern). On the one hand, there is the judgment that an institution has a valid claim to power because it operates in normatively appropriate ways (in the case of the police, that officers wield their authority in ways that align with people's sense of right and wrong, see Bradford et al. 2014a, b). On the other hand, there is the belief that the police have the right to enforce law and expect deference and compliance (Tyler 2006a, b).

Importantly for the current study, when researchers have operationalised legitimacy as institutional trust and obligation to obey (and modelled them as two separate explanatory variables), they have found that institutional trust is a more important predictor of willingness to cooperate than obligation to obey (e.g., Dirikx and van Den Bulck 2013, Reisig et al. 2007). Equally, when studies have defined legitimacy as normative alignment and obligation to obey, normative alignment explains more variation than obligation to obey (e.g., Jackson et al. 2013a). We therefore focus in the current study on normative alignment as a predictor of willingness to cooperate (we return to the issue in the limitations section at the end of the paper). Because of limited space in the survey, and because of prior evidence that it is less important than normative alignment when predicting cooperation (Tyler and Jackson 2014; Bradford et al. 2014c; Hamm et al. 2017), we did not measure obligation to obey. We provide a more complete rationale in the method section for the use of indicators of normative alignment to measure the perceived police appropriateness part of the legitimacy concept.

\section{Neighborhoods with the Norm (Not) to Cooperate: Evidence from Ethnographic Studies}

While studies have found significant variation across neighborhoods in willingness to cooperate with police, no quantitative study has addressed the possibility that some of this variation arises from place-based social norms. This is surprising, in part because ethnographic studies have shown considerable variability between communities in norms of cooperation with authorities (for a review, see Martin 2018). For instance, Stoutland (2001) conducted in-depth interviews with community members in four high-violence neighborhoods in Boston, all of which had been affected by a rise in youth violence. All four neighborhoods 
were generally anti-police and all four had recently experienced deterrence-based policy interventions, which meant that more officers were suddenly seen on the streets. Crucially for the current discussion, there was a strong norm not to cooperate with the police in one of the neighborhoods, with some community members convinced that "the police shared so few of their priorities that they were unwilling to cooperate with them" (p. 241). The prevailing mood was to avoid contact with officers. For instance, during a meeting between local agencies to discuss collaborating with police on neighborhood crime issues, some organizations declined to participate in any program because "they believed they would betray their constituents by working with the police" (p. 242). This may have been because most people in this community viewed the police as illegitimate and should not, therefore, be cooperated with. But it may also have been because there was a normative pressure not to cooperate, arising from a belief that if they did cooperate with the police, other community members would disapprove.

A similar example of residents feeling a sense of duty not to cooperate with the police is described by Ilan (2018). Based on a multilevel ethnography in a disadvantaged neighborhood of inner-city Dublin, Ireland, the author describes a cluster of community residents who were deeply embedded in street culture and who held hostile attitudes towards the police. A general perception of police illegitimacy was partly due to a sense of a collective memory-aside from individual negative experiences with officers, the notion of mistreatment was viewed as part of a wider pattern that included past stories circulating within the community. According to one resident, the police "stich people up, they plant drugs on you if they don't like you; they're all the same, they're all dirty bastards" (Ilan 2018, p. 689).

While these neighborhoods appear to have a strong norm not to cooperate with the police, a different Boston neighborhood described by Stoutland (2001) exhibited a weak norm, with generally critical views of the police, but with no overall consensus for other types of relationships. According to a young woman in this neighborhood, "police must remember they are often strangers with a badge and uniform in someone else's neighborhood" (p. 246), which signaled that officers were not seen as part of the community. However, Stoutland notes that citizens did report some good experiences: “...some residents also told me about their experiences in which particular officers had been consistently respectful and how this behavior influenced their feelings of security and views on Boston police" (p. 247). Residents were satisfied with this kind of increased police power when they were treated courteously, as they perceived it to be a sign of respect. The contrasting communities described by Stoutland demonstrates that there can be significant variability and room for alternative views even when the dominant norm is of negativity toward the police.

Another qualitative study that describes neighborhoods in which public willingness to cooperate with the police is in flux is that reported by Carr et al. (2007). Working in three high-crime neighborhoods in Philadelphia-one predominantly African-American, one predominantly Latino, and one predominantly white-the authors conducted in-depth interviews with delinquent and non-delinquent young men and women. All three neighborhoods had a homicide rate of at least 60 per 100,000 habitants (one of them reaching 150/100,000) and most residents lived in poverty. Overall attitudes towards the police tended to be critical and most youngsters were not willing to cooperate with legal authorities. However, Carr et al. (2007) reported that about one-third of residents in each of the three neighborhoods did not have a negative disposition toward the police, indicating some variability despite general hostility. Because residents of such communities did not hold uniformly critical views of the police, we could say that such neighborhoods do not have an established norm concerning cooperation with the police, with different residents holding 
different views on the desirability, or imperative, of doing so. In such a context, appropriate police behavior (however surprising it may be to residents who tended not expect fair treatment from the police) tended to be positively perceived and might have played a role in increasing public confidence. For instance, the authors describe the views of a 17 -yearold female who used to hold critical opinions about the police but recalls the kindness and concern shown to her by officers after events involving domestic violence (Carr et al. 2007, p. 460). Interestingly, despite the general negative disposition toward legal authorities in these neighborhoods, a common narrative among residents was that crime reduction would require the commitment of more police resources-i.e., most community members saw a crucial role for police and law enforcements in efforts to control crime.

While these studies did not directly measure a norm to cooperate with the police, they described neighborhoods where most residents believe they should not cooperate with legal authorities (see also Anderson 1990, 1999). This supports the idea that there is a shared social norm not to cooperate that is place-based. They also allude to neighborhoods where the norm to cooperate is not strong, i.e. where there was variability in residents' attitudes towards the police. Within this type of neighborhood, there should be space for procedural justice, trust and legitimacy to have some influence.

\section{Theory: Towards a Placed-Based Social Norms Explanation}

We posit a neighborhood-level explanation of people's willingness to cooperate with the police that is based on social norms operating at a small spatial scale. The legal socialization literature addresses how adolescents come to (a) internalise norms over time and within particular social contexts and (b) more broadly understand their relationship with the legal system and their rights, responsibilities and obligations with respect to the police and law. Tyler and Trinkner $(2018,4)$ document three processes at the heart of legal socialization:

(1) "The internalization of values about how legal authorities are supposed to act towards citizens and how people are supposed to behave towards authorities in their role as citizens;

(2) The formation of attitudes about the tangible representations of the law, including courts, laws, police, judges, and other legal authorities; and,

(3) The development of the cognitive and biological capacity to reason and think about the appropriate role for the law as a social institution in society."

As individuals move through adolescence into adulthood, they may or may not have internalised the norm that cooperating with the police is the right and expected thing to do. We focus on adults in the current study, and we propose that the neighborhood they live in as adults exerts an important additional effect on their willingness to cooperate. If, for instance, they live in a neighborhood where people are pro-police and would call them if they witnessed a crime, then this strengthens their willingness to act due to local normative pressures.

Our analysis is foreshadowed to some degree by a study in Japan. Tsushima and Koichi (2015) used data from a nationally representative survey that measured people's willingness to report a crime to the police, provide information about the culprit, and give evidence in court. They found little variation in people's willingness to cooperate, in that most 
people would do so: the mean on a composite index was 3.4 on a scale from 1 to 4 and the standard deviation was 0.6. Legitimacy was not a significant predictor of cooperation and, although the authors did not discuss it, it is plausible that the norm to cooperate is generally quite strong in the general Japanese population. That is to say, most people in Japan are willing to cooperate with police because it is a shared standard and expectation of appropriate behaviour, so there is little variation left over for legitimacy to explain.

In a related study, Antrobus et al. (2015) found, with a sample of Australians, that an individual's beliefs about the extent to which neighborhood residents accepted police legitimacy was associated with their sense of duty to obey officers. Moreover, perception of police procedural justice was a less important predictor of duty to obey when endorsement was strong. On this basis, the authors concluded that "those who feel there are strong community norms around police legitimacy may view police as legitimate regardless of how they are treated [by police]. For those who live in communities with weaker norms about police legitimacy, being treated fairly by police has a greater opportunity to shape and change their own views" (Antrobus et al. 2015, 15).

We hypothesize that a similar relationship exists between legitimacy and cooperation. Why might legitimacy be related to willingness to cooperate only when the norm to cooperate is weak? First, living in a neighborhood with a strong norm to cooperate with police is likely to lead to internalisation of that social norm, and we propose that this more proximate group-level force over-rides the effect of individual perceptions of police legitimacy, i.e. most people will be willing to cooperate precisely because it is the right and expected thing to do, irrespective of what they think about the legitimacy of the police. Second, when the norm is weak, there is space for legitimacy to play a more important role. To understand why legitimacy motivates proactive helping behaviour, we draw on the notion of normative alignment. People judge the right to power of an institution on the basis that the institution acts in appropriate and justifiable ways (Tyler and Jackson 2014; Trinkner et al. 2018). When police officers are seen to act according to the societal norms that proscribe how authority figures should behave, citizens confer to the institution a sense of normativity (a property that leads people to believe that the institution is moral, just and appropriate) that in turn activates a sense of reciprocity-if authorities act appropriately, then citizens should also act appropriately (e.g., report crimes to the police), because they see this as part of being a law-abiding citizen (Jackson et al. 2012, 2013a). However, in a neighborhood with a strong norm to cooperate, everybody is willing (because of the strength of social norms in general), so there is no supplementary role for legitimacy to play.

\section{Analytical Strategy}

Our goal is, then, to assess whether the strength of the norm to cooperate varies across neighborhoods and examine whether a positive role of perceived police legitimacy is limited to neighborhoods where the norm to cooperate is weak. Brunton-Smith et al. (2018) used a mixed-effects location-scale model to account for the extent to which community member are seen to share values and be willing and able to act on behalf of the collective achieve to achieve social goods. Estimating the central tendency and variance of clusterlevel collective efficacy in neighborhoods across London, they found a stronger negative effect of mean levels of collective efficacy on worry about violent victimization when there was high consensus (i.e. low variance) in those neighborhoods. 
We apply the same analytical strategy to people's willingness to cooperate with the police. Our approach comprises five sequential stages. First, we sample a total of 1057 individuals living in 98 small-scale geographical locations (that we call 'hexagons' given their spatial patterning, for more details see the method section) that we treat as neighborhoods. Second, we measure people's expressed willingness to cooperate with the police using a vignette (witnessing a crime in which somebody was knocked to the floor and a wallet was stolen, and asking whether the respondent would call the police, identify the person(s) involved, and be willing to give evidence against them in court). This is the expressed belief that proactively helping the police and criminal courts is the right thing to do, i.e. things that they are prepared to if the need arose. Third, we model the cluster-level mean and variance of willingness to cooperate within each neighborhood using a mixed-effects location-scale model. Fourth, we define neighborhoods as having a strong norm to cooperate when the mean is high and the variance is low, i.e. where most people report that they would proactively cooperate with the police. Conversely, if the mean is low and the variance is low, the norm not to cooperate is strong, as most people report that they would not cooperate. Finally, we test whether legitimacy only plays a role in the neighborhoods that are in between these poles, specifically in neighborhoods where the variance is high, i.e. where normative pressure seems to be low because there is no strong agreement among residents that cooperate is, or is not, the right thing to do.

Why do we infer that a norm to cooperate is present in neighborhoods where the mean is high and the variance is low, and that a norm not to cooperate is present in neighborhoods where the mean is low and the variance is low? Social norms are shared standards or expectations about appropriate behaviour within a given social group, which could be a family, a friendship group, an institution, a region, a nation and so on. It is not necessary for all individuals to internalise the norm, but within a particular social group (e.g., within a particular neighborhood), most group members need to express an intention to voluntarily cooperate for the norm to be strong; the idea of relative consensus is central to the notion of a norm. If most people in a strong norm neighborhood are willing to cooperate, we infer that most people in that locality tend to believe that it is right and proper to conform to this expectation, and most people tend to believe that most other people in that locality also believe the same thing and disapprove of those who do not. In such a context, we suggest, there is a shared normative 'force' that provides a motivation to cooperate with the police that is place-based. This creates a more proximate individual-level motivation to cooperate with the police compared to perceived police legitimacy, because individuals have internalized the norm to cooperate, they believe that is the right thing to do and that others in their neighborhood will disapprove if they did not cooperate. We use expressed willingness to cooperate as a way of measuring this at the individual-level. If the norm to cooperate with the police is strong in a particular neighborhood-i.e. if most people report being willing to cooperate - then we infer that it is a shared expectation and requirement that people within that neighborhood will cooperate with the police, not because of any existing law or rule, but because it is generally accepted that this is what people should do. Crucially, most people need to report being willing to cooperate if the social norm is estimated to be strong in that locality.

\section{Data}

The data used in this paper were collected on behalf of a large metropolitan police force by the survey company Opinion Research Services in the summer of 2018. The survey used a highly clustered sampling frame, in which all the primary sampling units-which we 
use to denote neighborhoods-were selected in high crime locations (defined as being in the top $10 \%$ of areas force-wide). By implication, the inferences and conclusions we draw based on these data are limited to high crime areas, and may not generalise to the general population.

Neighborhoods play a central role in developing and maintaining social ties and strengthening community cohesion. Much research has found that shared places such as parks, high streets, cafés or community centres act as social conduits creating an opportunity for interaction among neighborhood residents (Hipp et al. 2018; Wo 2016). Ultimately, these social interactions engender an augmented sense of community, resulting in enhanced community cohesion. In turn, this increased cohesion imposes a form of informal social control on citizens and curbs (perceived and actual) crime and disorder in the neighborhood (Brunton-Smith et al. 2014; Papachristos et al. 2011; Sampson 2012).

The well-known analytical challenge of the concept of the neighborhood is that neighborhoods as colloquially understood lack well-defined boundaries, making it difficult to define ecologically persuasive units. One of the major-but often unavoidable-weaknesses of neighborhood studies is their reliance on administrative boundaries which do not map well on to the communities they seek to represent. This can lead to artificial positive or null-findings due to the mismatch in the aggregation of the social context of interest (Hipp 2007; Hipp et al. 2012). Focusing on real communities is important, as the increased number of interactions among residents is a key element of enhancing community cohesion and informal social control in the area (Hipp et al. 2018; Wo 2016), which, in turn, lead to increased cooperation.

In our study, we rely on smaller geographical areas called 'hexagons', which were created by the large Metropolitan Police Force to be walkable and easily monitored by local police officers while being on the beat. They were also tailored so they would consider natural (e.g., river dividing communities) and artificial (e.g., train-tracks going through a certain neighborhood) boundaries. Hipp et al. (2014) referred to these physical dividing lines as 'wedges', which normally reduce social interactions in a neighborhood and negatively impact the perception of neighborhood attachment, perceived neighborhood cohesion, and engagement in neighboring behaviors. Similarly, Wickes et al. (2019) derived their neighborhood fragmentation index based on the presence of 'social wedges' (railways, motorways, rivers), features that conceivably reduce the propensity of social interactions in a given neighborhood. The hexagons we use only cover spatially contiguous sections of a location without similar wedges present, so it is more likely that the residents would be able to experience routine encounters, interact with each other or otherwise mingle on a regular basis, potentially also affecting their behaviour and sense of community.

These hexagons are also different from census Lower Super Output Areas (LSOA, commonly used in UK studies) as they cover geographical areas of slightly different sizes, while their population (and the number of households) might differ-as it is common with real communities. By contrast, LSOAs are less concerned about the size of the geographical area instead, they try to achieve consistency in population size. As demonstrated by several authors, geographical proximity is more pertinent to defining neighbourhoods than population size (e.g., Hipp et al. 2012, 2018), which again leads us to believe that hexagons have more desirable characteristics than LSOAs. Stratified clustered random sampling strategy was used to select neighborhood residents with strata defined by eight Neighborhood Policing Units (NPU), which were further divided into four strata each resulting in 32 strata overall. Within 30 strata, 3 hexagons were randomly selected and in the two strata 4 hexagons were selected as primary sampling units, yielding 98 in total. In each sampled hexagon an average of 11 face-to-face interviews were conducted giving a total of 
1057 (range 1-21, with more than $60 \%$ of hexagons resulting in 10 or 11 interviews). ${ }^{1}$ The response rate was $32 \%$. In all analyses a weight is applied.

\section{Measures}

\section{Willingness to Cooperate}

We assess residents' willingness to cooperate with the police using a vignette in which a crime is witnessed involving somebody being knocked to the floor and an item of property stolen. Participants were asked "how likely or unlikely would you be to call the police?", with response options ranging from 'not at all likely' (1) to 'very likely' (4). Those reporting they would be willing to contact the police were asked two follow up questions- - "how willing or unwilling would you be to identify the person who did it?" and "give evidence in court against the person?"-with responses ranging from 'not at all willing' (1) to 'very willing' (4). Those reporting they were not likely to call the police were allocated scores of 1 on the second and third items to reflect the fact that calling the police in this situation is a necessary precondition for the subsequent actions.

The three items are combined using factor analysis to form a willingness to cooperate scale (with factor loadings of $0.74,0.92$, and 0.85 and a Cronbach's alpha of 0.88). Note in the statistical modelling and results section, for the sake of brevity we refer to this construct as 'willing cooperation.'

\section{Normative Alignment}

We operationalize legitimacy as normative alignment (Jackson et al. 2012, 2013a; Tyler and Jackson 2014). Proxy measures are generally preferred because it is difficult to measure people's perceptions of the right to rule via direct self-report ('do you think the police have a moral right to power'?) and authority to govern ('do you think the police have the right to tell you what to do?'). We measure normative alignment using two questions: “the police have the same sense of right and wrong as me' and "I support the way the police usually act". The mean of these two items is calculated to form a scale (correlation of 0.57 ) that measures the belief that the officers who embody the institution behave in normatively appropriate ways, i.e. in ways that align with people's values. The rationale here is that if the institution represents values that people believe to be important, they will consent to its right to power because they believe that authority is being exercised appropriately.

\section{Collective Efficacy}

We measure collective efficacy (Sampson et al. 1997, 918) at the neighborhood level by combining four items using factor analysis to form a uni-dimensional scale and then aggregating it to the neighborhood level. We use the following items (factor loadings in parentheses):

\footnotetext{
${ }^{1}$ The sampling strategy produces a random distribution of hexagons across the area, with very little evidence of hexagons being sampled from contiguous LSOAs. Additional analyses revealed no evidence of spatial autocorrelation with no clear pattern to nearest neighbor correlations (see Appendix A.1). We therefore do not include spatially lagged measures in our models.
} 
- People in this neighborhood can be trusted (0.68)

- You can see from the public space here that people take pride in their environment $(0.76)$

- Local people and authorities have control over public space here (0.68)

- If I sensed trouble whilst in this neighborhood, I could get help from the people who live here $(0.62)$

\section{Covariates}

We include age, gender and an indicator of belonging to a minority ethnic group as individual level controls. At the neighborhood level we control for the Index of Multiple Deprivation (IMD), with higher scores representing less deprived neighborhoods (we return to the issue of other neighborhood level factors in the limitations section towards the end of the paper).

\section{Analysis}

To assess the strength of the social norm to cooperate across neighborhoods, we use a mixed effects location-scale model (Hedeker et al. 2008). Like standard mixed effects models, this allows us to generate empirical bayes estimates of between neighborhood differences in mean levels of cooperation and to distinguish this from differences between individuals within each neighborhood. These estimates are 'shrunk' back to the global mean as a function of the group sample size, enabling more robust inferences. By including an additional random effect in the individual-level model, we are able to generate equivalent estimates of between neighborhood differences in the extent of within-neighborhood variation (see e.g. Browning et al. 2016; Brunton-Smith et al. 2018; Hipp et al. 2018). We also extend the location-scale model by incorporating an individual level measurement model to correct for measurement error in our indicators of neighborhood norms in the following way. Let $y_{h i j}$ denote the observed response on item $h(h=1, \ldots, H)$ for respondent $i(i=1, \ldots, N)$ in neighborhood $j(j=1, \ldots, J)$. The measurement model can then be written as

$$
\begin{gathered}
y_{h i j}=\eta_{i j}+\varepsilon_{h i j} \\
\varepsilon_{h i j} \sim N\left(0, \sigma_{\varepsilon}^{2}\right)
\end{gathered}
$$

where $\eta_{i j}$ denotes the true willing cooperation score for respondent $i$ and $\varepsilon_{h i j}$ the normally distributed measurement error. The true score $\eta_{i j}$ can then be modelled using the structural model:

$$
\begin{gathered}
\eta_{i j}=\mathbf{x}_{i j}^{\prime} \boldsymbol{\beta}+u_{j}^{[1]}+e_{i j}, \\
u_{j}^{[1]} \sim N\left(0, \sigma_{u[1]}^{2}\right), \\
e_{i j} \sim N\left(0, \sigma_{e_{i j}}^{2}\right)
\end{gathered}
$$


where $\mathbf{x}_{i j}$ is a vector of respondent and neighborhood level covariates with coefficients $\boldsymbol{\beta}$ and $u_{j}^{[1]}$ is a random intercept effect representing remaining unobserved neighborhood influences on $\eta_{i j}$. The respondent-specific random effect $e_{i j}$ captures unobserved respondent characteristics which are predictive of willing cooperation. The random effects are assumed mutually independent, independent of the covariates, and normally distributed. The random effect variance $\sigma_{u}^{2}$ captures the variability in adjusted true scores across neighborhoods, while the respondent variance $\sigma_{e_{i j}}^{2}$ measures the variability in respondents' true cooperation ratings that is unexplained by the fixed and random effects. The respondent variance is therefore corrected for random measurement error through the measurement model in Eq. 1.

To assess how neighborhoods differ in the shared norm to cooperate, we expand the structural model by removing the restriction of constant within-neighborhood variance in Eq. (2). The adjusted respondent true score variance $\sigma_{e_{i j}}^{2}$ is then modelled using a log-linear link function

$$
\begin{gathered}
\ln \left(\sigma_{e_{i j}}^{2}\right)=\mathbf{w}_{i j}^{\prime} \boldsymbol{\alpha}+u_{j}^{[2]}, \\
u_{j}^{[2]} \sim N\left(0, \sigma_{u[2]}^{2}\right),
\end{gathered}
$$

where $\mathbf{w}_{i j}$ includes a vector of respondent and neighborhood level covariates with coefficients $\boldsymbol{\alpha}$, and $u_{j}^{[2]}$ is an additional neighborhood random effect. The inclusion of covariates in Eq. (3) allows neighborhoods to have differential effects on the mean (location) and the variance (scale) of true scores. The inclusion of $u_{j}^{[2]}$ allows for residual influence of neighborhood differences on the scale of true scores. The variance component $\sigma_{u[2]}^{2}$ summarises the variability in the scale of respondents' answers across neighborhoods. The covariance of the random effects is estimated as $\sigma_{u[1] u[2]}$ :

The estimated model residuals, $\hat{u}_{j}^{[1]}$ and $\hat{u}_{j}^{[2]}$, are used to examine whether the strength of norms to cooperate moderates the relationship between normative alignment and individual cooperation. To do this we distinguish four categories of neighborhood: neighborhoods with: 1 . a low mean and low variance $(l M l V) ; 2$. a low mean and high variance $(l M h V) ; 3$. a high mean and low variance $(h M l V)$; and 4. a high mean and high variance ( $h M h V)$. Interactions between these neighborhood categories and normative alignment (na) are added to the model in Eq. (4):

$$
\begin{aligned}
y_{i j}= & \beta_{1} n a_{i j}+\beta_{2} l M h V_{j}+\beta_{3} h M l V_{j}+\beta_{4} h M h V_{j}+\beta_{5} n a_{i j} l M h V_{j}+\beta_{6} n a_{i j} h M l V_{j} \\
& +\beta_{7} n a_{i j} h M h V_{j}+\mathbf{x}_{i j}^{\prime} \boldsymbol{\beta}+u_{j}+e_{i j},
\end{aligned}
$$

Willingness to cooperate, $y_{i j}$, and normative alignment, $n a_{i j}$, are derived as uni-dimensional scales using factor analysis. Our expectation is that neighborhoods with a high mean and low variance have a strong norm to cooperate while neighborhoods characterised by a low mean and low variance have a strong norm not to cooperate. Conversely, neighborhoods with a low mean and high variance, or high mean and high variance have weaker norms to cooperate. Neighborhoods are defined as high mean or high variance using a threshold set at $50 \%$ - high mean if $\hat{u}_{j}^{[1]}$ is in the top $50 \%$ of the distribution, $\sigma_{u[1]}^{2}$, and high variance if $\hat{u}_{j}^{[2]}$ is in the top $50 \%$ of the distribution, $\sigma_{u[2]}^{2}$. Our results are qualitatively robust 


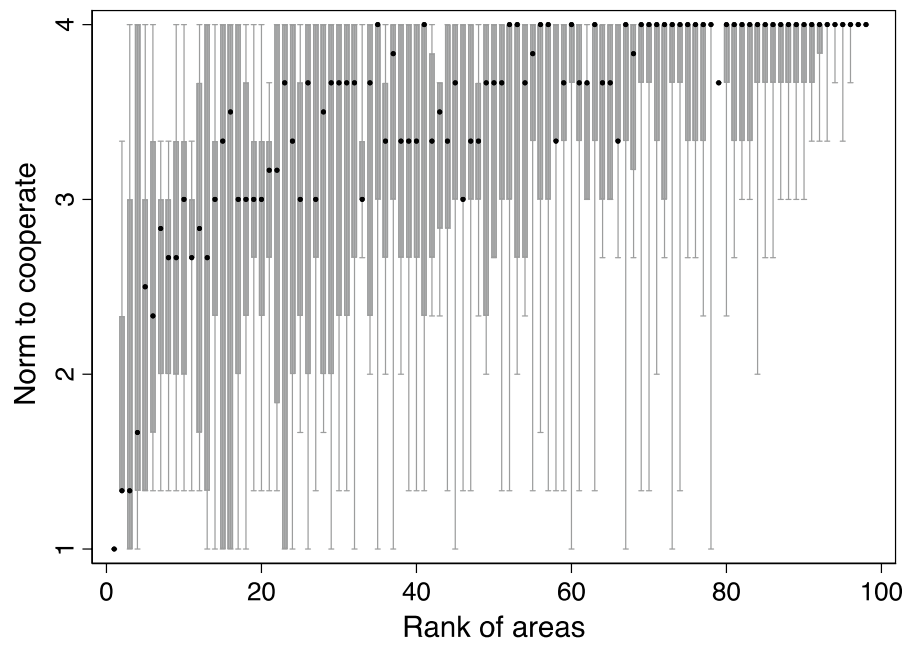

Fig. 1 Neighborhood willingness to cooperate (mean and range)

to variation of this threshold at the 25th, 33rd, 66th or 75th percentiles of the distribution (see Appendix Section A.2, Tables A1-A4). ${ }^{2}$

Models are estimated using Markov Chain Monte Carlo (MCMC) methods implemented in the Stat-JR statistics package (Charlton et al. 2013; Leckie et al. 2014). Diffuse prior distributions are specified for all parameters, and all models are run using three MCMC chains with dispersed starting values, each with a burn-in period of 50,000 iterations and a monitoring period of 50,000 iterations. Visual assessments of the parameter chains and standard MCMC convergence diagnostics suggest that these periods are sufficiently long to generate robust parameter summaries (Spiegelhalter et al. 2002). The results we present are the means, standard deviations and 95\% coverage intervals of the 150,000 monitoring iterations pooled across the three chains. These quantities are analogous to the parameter estimates, standard errors and confidence intervals obtained in a frequentist analysis. Models assessing whether the strength of norms to cooperate moderate the effect of normative alignment are estimated using restricted maximum likelihood in Stata.

\section{Results}

Figure 1 displays the overall pattern of differences in willingness to cooperate across the sample of neighborhoods. Neighborhoods are ranked by the mean score on the three cooperation measures (medians are shown with black dots), with the middle 50\% of individual scores shown by the thick grey bars and the full range given by the capped bars. The levels of cooperation are generally high across all neighborhoods with the mean greater than three in more than two-thirds of local areas, although there is a minority of neighborhoods

\footnotetext{
${ }^{2}$ Models estimated using the full distributions of $\hat{u}_{j}^{[1]}$ and $\hat{u}_{j}^{[2]}$ and 3-way interactions with normative alignment were also estimated, leading to the same substantive conclusions (see Appendix A.3, Tables A5-A6). However, we prefer the simplicity of presentation of the categorical 2-way interaction models.
} 
Table 1 Norm to cooperate-location scale model results

\begin{tabular}{|c|c|c|c|c|c|c|c|c|}
\hline & \multicolumn{4}{|c|}{ Model 1: Empty } & \multicolumn{4}{|c|}{ Model 2: Explanatory variables } \\
\hline & \multirow[b]{2}{*}{ Mean } & \multirow[b]{2}{*}{ SD } & \multicolumn{2}{|c|}{$\begin{array}{l}95 \% \text { coverage } \\
\text { interval }\end{array}$} & \multirow[b]{2}{*}{ Mean } & \multirow[b]{2}{*}{ SD } & \multicolumn{2}{|c|}{$\begin{array}{l}95 \% \text { coverage } \\
\text { interval }\end{array}$} \\
\hline & & & $2.5 \%$ & $97.5 \%$ & & & $2.5 \%$ & $97.5 \%$ \\
\hline \multicolumn{9}{|l|}{ Location equation } \\
\hline Beta (location intercept) & 3.37 & 0.05 & 3.27 & 3.46 & 3.43 & 0.05 & 3.33 & 3.54 \\
\hline Female & & & & & -0.05 & 0.05 & -0.14 & 0.04 \\
\hline Black and minority ethnic & & & & & -0.15 & 0.06 & -0.26 & -0.04 \\
\hline Age & & & & & 0.01 & 0.01 & -0.02 & 0.03 \\
\hline Collective efficacy & & & & & 0.22 & 0.10 & 0.02 & 0.42 \\
\hline IMD & & & & & 0.02 & 0.02 & -0.02 & 0.06 \\
\hline \multicolumn{9}{|l|}{ Scale equation } \\
\hline Alpha (scale intercept) & -1.01 & 0.13 & -1.28 & -0.76 & -1.11 & 0.16 & -1.43 & -0.81 \\
\hline Female & & & & & 0.19 & 0.14 & -0.08 & 0.47 \\
\hline Black and minority ethnic & & & & & -0.01 & 0.17 & -0.34 & 0.31 \\
\hline Age & & & & & -0.07 & 0.04 & -0.15 & 0.00 \\
\hline Collective efficacy & & & & & -0.22 & 0.30 & -0.81 & 0.37 \\
\hline IMD & & & & & 0.04 & 0.06 & -0.08 & 0.17 \\
\hline Location variance & 0.15 & 0.03 & 0.10 & 0.22 & 0.11 & 0.03 & 0.07 & 0.18 \\
\hline Covariance & -0.10 & 0.06 & -0.22 & 0.01 & -0.03 & 0.05 & -0.13 & 0.08 \\
\hline Scale variance & 0.96 & 0.28 & 0.51 & 1.62 & 0.92 & 0.29 & 0.47 & 1.59 \\
\hline Measurement error & 0.39 & 0.01 & 0.37 & 0.41 & 0.39 & 0.01 & 0.37 & 0.41 \\
\hline ICC (population average) ${ }^{\mathrm{a}}$ & 0.20 & & & & & & & \\
\hline Individuals/neighborhoods & $1039 / 98$ & & & & $1039 / 98$ & & & \\
\hline
\end{tabular}

${ }^{\text {a }}$ The population average ICC is given by $\sigma_{u[1]}^{2} /\left[\sigma_{u[1]}^{2}+\exp \left(\boldsymbol{\alpha}+0.5 \sigma_{u[2]}^{2}\right)\right]$

with substantially lower mean cooperation scores. There is little sign in Fig. 1, however, of many neighborhoods where there is a norm not to cooperate (only $12 \%$ of neighborhoods have a mean score below 3). This would be evident if we observed more neighborhoods with a low mean (closer to the bottom end of the scale) and low variance. The norm to cooperate in these neighborhoods also appears to be less consensual, with the differences between respondents generally more marked (i.e. with higher variance) when the norm to cooperate is lower. There is also little evidence of any substantial group of neighborhoods with a high mean and high variance.

Table 1 includes estimates from the mixed-effects location scale models. Model 1 (without covariates) shows how neighborhoods differ in the mean level of cooperation (the location equation) and the within neighborhood variance (the scale equation). The large coefficient for the intercept in the location Eq. (3.37) shows that willingness to cooperate is generally high across neighborhoods, though there is also substantial variability in this average, with the intra-class correlation showing that approximately $20 \%$ of the total variation is between neighborhoods (adjusting for measurement error).

We also find substantial differences in the degree of within neighborhood variation. The coefficient for the scale intercept of -1.01 equates to a population average level-1 variance 


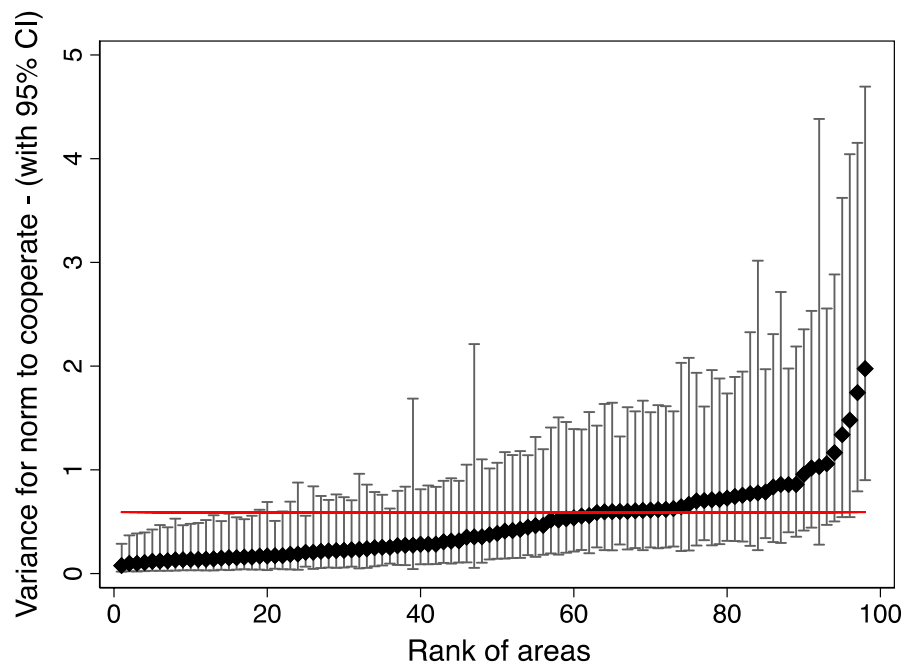

Fig. 2 Neighborhood-specific variance in willingness to cooperate

of 0.65 , but there is also a significant scale variance of $0.96 .^{3}$ To put the magnitude of this term in context, Fig. 2 plots the within neighborhood variance estimates for our all neighborhoods, alongside the population average variance (horizontal red line). This shows that while more than half of neighborhoods exhibit little within neighborhood variation in willing cooperation (left side of the graph), a small number of areas exhibit quite high levels of variation. The negative covariance between the location and scale intercepts shows that neighborhoods with a lower mean level of cooperation tend also to have a higher variance.

Model 2 includes individual and neighborhood characteristics in the location and scale equations. Here we see that people tend to be more willing to cooperate with the police in neighborhoods that are high in collective efficacy, and that have lower levels of deprivation. At the individual level, willingness to cooperate is lower for residents from a black or minority ethnic background $(-0.15)$. In the scale equation ${ }^{4}$ we find evidence that the cooperation ratings of older people are less variable $(-0.07)$. However, there is no indication that differences in the levels of within-neighborhood variance are associated with collective efficacy or deprivation, with the $95 \%$ credible intervals including 0 .

We next assess whether these differences in neighborhood contexts affect the relationship between normative alignment and individual willingness to cooperate (Table 2). We use the estimated location and scale residuals from Model 1 to identify neighborhoods with high and low mean cooperation scores and high and low variances. These indicators are then interacted these with individual-level normative alignment. Focusing first on differences in the average willingness to cooperate (Model 3) we find that in a neighborhood that has a low cluster-level mean, cooperation at the individual level is low, though there is a strong positive association between normative alignment and individual cooperation (0.21). Conversely, in neighborhoods with a high cluster-level mean, cooperation is high

\footnotetext{
3 The level-1 variance is defined as $\sigma_{e}^{2}=\exp \left(\boldsymbol{\alpha}+0.5 \sigma_{u[2]}^{2}\right)$.

${ }^{4}$ Note that a positive coefficient in the scale equation corresponds to an increase in level-1 variation (compared to the population average), and a negative coefficient represents a decrease in variance.
} 


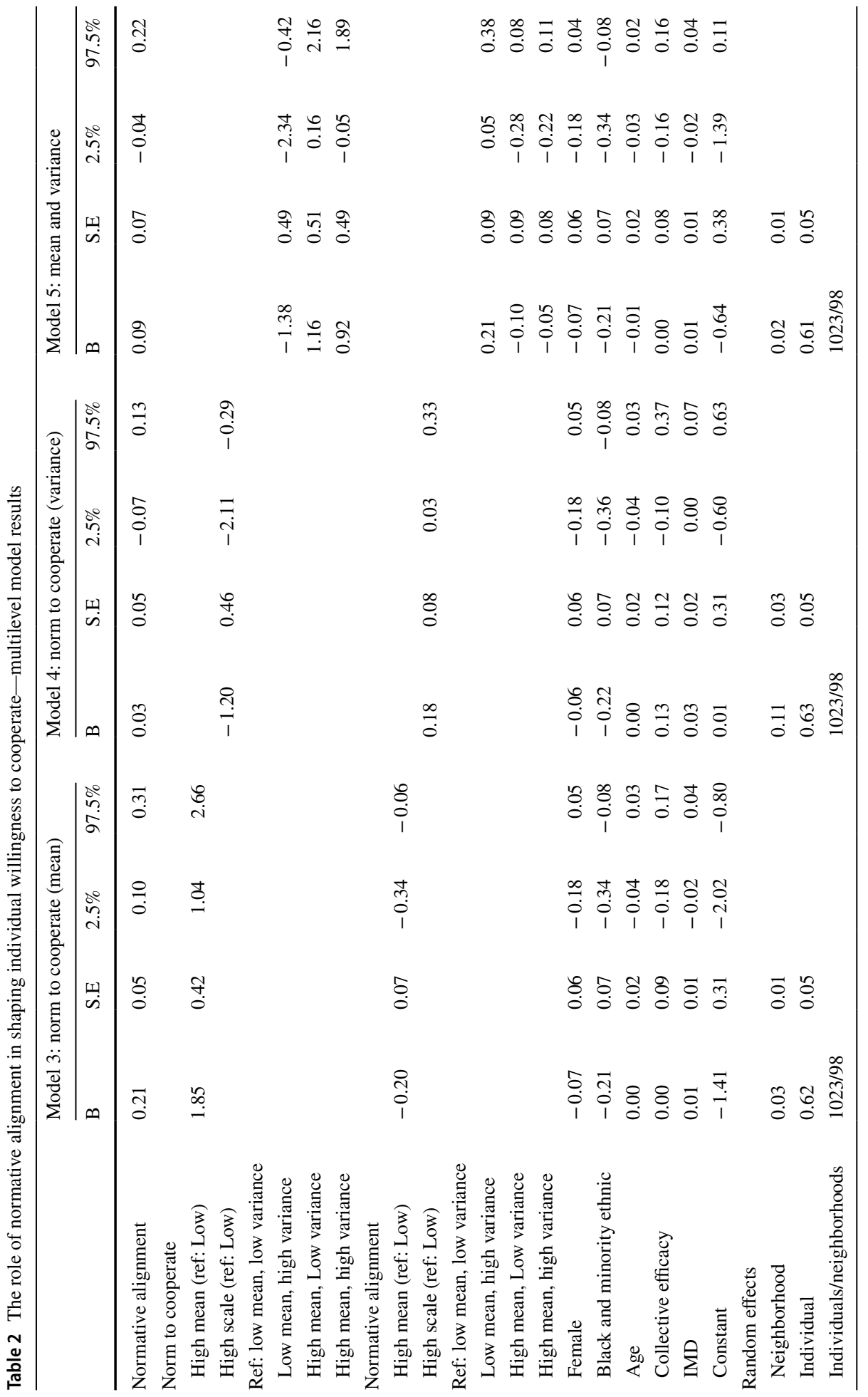




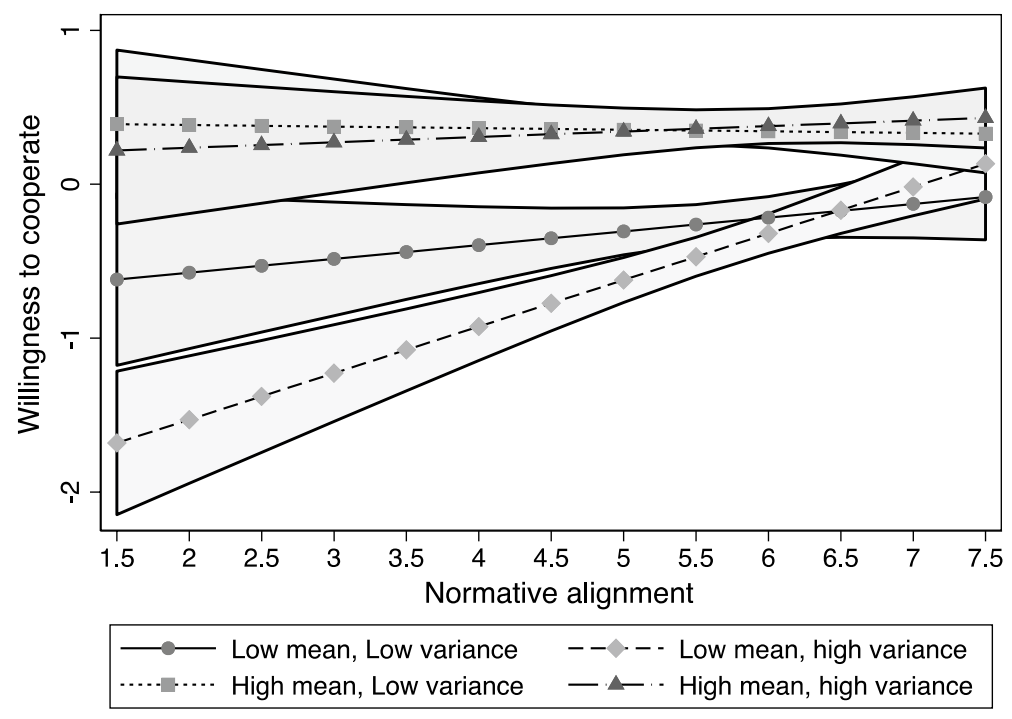

Fig. 3 The effect of normative alignment on willingness to cooperate across neighborhoods

and unrelated to normative alignment $(0.21-0.20=0.01)$. In other words, in the absence of an existing local norm to cooperate, legitimacy plays an important role but when there is a strong local norm to cooperate, there is no additional role for legitimacy. Consistent with our expectations, in Model 4 cooperation is also generally lower in neighborhoods where there is less consensus (high variance) about the norm to cooperate. We also find some support for the expectation that the effect of normative alignment is stronger in these neighborhoods (although this is only significant at the $10 \%$ level), with legitimacy playing a more substantial role when the norm to cooperate is ambiguous.

Model 5 includes the interactions between the mean and variance parameters and fitted values for this model are displayed graphically in Fig. 3. We find that only in neighborhoods classified as having a weak norm not to cooperate is there a strong association between normative alignment and cooperation. Indeed, when normative alignment is at its maximum, there is a suggestion that this may have the effect of substituting for the effect of the neighborhood norm. In contrast, we find no significant differences between residents of neighborhoods that have an unambiguous cooperation norm.

\section{Conclusions}

Norms offer socially-shared standards for appropriate and inappropriate behaviour that govern what is acceptable and unacceptable. They help to make people in the same neighborhood accountable to each other, to demand and expect others to act in a particular way (Brennan et al. 2013). In this paper, we have considered the idea that to cooperate with the police is a placed-based norm and, moreover, that social norms are the dominant account of public motivation-separate from perceptions of police legitimacy-when the grouplevel norm is strong in one's immediate neighborhood. Capitalising not only on the data structure of our study but also on recent advances in modelling the cluster-level mean and 
variance, specifically the mixed-effects location-scale model (Hedeker et al. 2008; Leckie et al. 2014; Brunton-Smith et al. 2018), our findings suggest that the norm to cooperate exists and varies in strength from neighborhood to neighborhood, at least in the current geographical context of high-crime parts of a large metropolitan area of England. Interestingly, there was no locality in our data where the mean was close to the bottom end of the scale and the variance was low. This contrasts with some US-based qualitative work that describes certain communities in large metropolitan cities in which to cooperate with the police almost makes one a 'pariah'.

Procedural justice theory (PJT) is a popular account of how police can encourage public cooperation by generating consensual rather than coercive connections between powerholders and subordinates: procedural justice generates legitimacy and legitimacy generates cooperation. We found evidence for a boundary condition of procedural justice theory. In neighborhoods where the norm was strong, the shared social consensus seemed to dominate, operating as the proximate factor explaining relatively widespread public cooperation with the police. Nearly everyone in the neighborhood reported being willing to cooperate, which we infer to mean that they believed that it was the right and proper thing to do. By contrast, legitimacy only played a role in neighborhoods in which the norm was in flux, i.e. low cluster-level mean and high cluster-level variance (where low mean was relative rather than absolute, so lower than high mean neighborhoods, but not close to the bottom end of the scale of cooperation). The over-arching message is that people's relationships with police (which we have modelled as the extent of willing cooperation) cannot be considered in isolation from their relationships with each other (which we have modelled as neighborhood norms). The individual level focus dominant within most PJT research-and indeed the wider body of work on public attitudes toward police-needs therefore to be complemented by a focus on group norms, and how placed-based social norms interact with people's attitudes towards legitimacy in generating public cooperation with police.

This finding - that police legitimacy only 'kicks in' when local social norms concerning cooperation are relatively weak-is important in itself. It suggests, for example, that legitimacy building efforts will only see a 'return' of increased cooperation when they are focussed on particular neighborhoods. Although there is a possibility that due to diversion of resources to certain areas other (not targeted) neighborhoods might suffer, recent policing studies have found only very limited negative side-effects during focused interventions (Groff et al. 2015; Sidebottom et al. 2017). It also indicates some of the rarely explored limits of PJT, precisely because it suggests that some of the core pathways proposed by this theory, in this case from legitimacy to cooperation, are less salient and perhaps even redundant in some social contexts. But this finding, and the method used to produce it, could be built on in a number of instructive ways.

Beyond demonstrating the value of the mixed-effects location-scale model (which we consider in some detail in the final section) our study also contributes to community criminology by relying on small geographical areas, the so-called hexagons. Several studies in community criminology struggle with the operationalisation and identification of genuine communities as a meaningful unit of analysis (Hipp 2007; Hipp et al. 2012; Wickes et al. 2019). Due to their unique features, these hexagons are more likely to represent real neighborhoods where people interact with each other hence making the emergence of shared norms more likely. Future studies could benefit from analysing areas designed along similar principles.

In addition, we extended existing work that has used a location-scale approach by incorporating a measurement error model alongside the standard location and scale effects. This 
has enabled a more robust estimate of the variability in the mean and within-cluster variance across neighborhoods.

\section{Limitations}

Because it was constrained by the wider study of which it was part, the survey used in this paper was limited in size and content. With more space we would have measured not only people's willingness to cooperate using a vignette but also more direct measures of the degree to which people have internalized the norm to cooperate. This might involve measuring the belief that others in one's social group tend to believe that it is right and proper to conform to this expectation, the belief that most other people in one's social group also believe the same thing, the expectation that others conform (and to disapprove of those who do not), and the expectation that others expect each other to also conform. Future studies should use more comprehensive measures of the norm to cooperate and use neighborhood-level estimates of shared norms to predict individual willingness to cooperation, as well as include survey measures of self-reported actual behaviour (augmented perhaps by police data on things like reporting of crime and calls for service). This would allow researchers to avoid the charge of mild tautology in using cluster-level mean and variance estimates of a given construct to predict within-cluster individual-level variation in the exact same construc

The measures of collective efficacy ('People in this neighborhood can be trusted', 'You can see from the public space here that people take pride in their environment', 'Local people and authorities have control over public space here' and 'If I sensed trouble whilst in this neighborhood, I could get help from the people who live here' align with how the construct has been measured in a number of UK studies (e.g. Sutherland et al. 2013; Brunton-Smith et al. 2014), in that they capture a sense of shared trust, shared ownership and control of public space, and willingness to intervene (informal social control). It should be noted, however, that Brunton-Smith et al. (2014) used six measures of collective efficacy, one of which was 'The people who live here can be relied upon to call the police if someone is acting suspiciously'. Our measures also depart a little bit from those of Sampson et al. (1997), who had five measures of informal social control and five measures of social cohesion. Future studies would benefit from using a more complete scale of collective efficacy. They would also benefit from measuring both aspects of perceived police legitimacy, i.e. not just normative alignment but also duty to obey (for discussion, see Trinkner 2019; Posch et al. forthcoming).

Tests of PJT tend to compare the extent to which legitimacy, on the one hand, and instrumental factors like perceived police effectiveness and fear of crime, on the other, predict cooperation. The current study did not include measures of effectiveness and fear of crime for reasons of space. Because we could only include legitimacy in our analysis, it may be that the positive partial association between legitimacy and cooperation (in neighborhoods where then norm to cooperate was weak) would be attenuated if we added effectiveness and fear of crime to the model. It is for future studies to assess this. Researchers could also assess whether there are neighborhoods that have a strong norm not to cooperate, like for instance in certain communities in major metropolitan cities in the US.

The concentration in this study on high crime neighborhoods within the large metropolitan areas of England is in many ways a positive factor, in as much as these are neighborhoods where it might be expected that legitimacy and cooperation are low, or at least 
in doubt. But in future development of this work, we aim to assess the extent to which our findings generalise to the full general population of neighborhoods and individuals. Our conclusions are also not immune from the Modifiable Areal Unit Problem. Whilst we were able to capitalise on a spatial geography that more closely approximates meaningful neighborhoods for residents (aligning with major natural and artificial boundaries) and police (walkable and easily monitored), and initial exploratory analysis revealed no clear evidence of spatial autocorrelation, like all ecological studies it is remains possible that different conclusions would be drawn if a different spatial aggregation was used.

Whilst interviews were successfully completed with an average of 11 people within each sampled hexagon, there were a small number of hexagons $(n=3)$ where only one interview was achieved. The neighbourhood-level cooperation measures-mean and variance-used in this analysis are empirical Bayes estimates (i.e. are shrunk to the grand mean as a function of sample size) so automatically correct for this potential problem. To assess the potential impact of hexagons with one achieved interview on our results we reestimated the results with the three singleton hexagons removed, yielding almost identical results (see Appendix A.4).

Because of the innovative nature of the sampling process, there are no demographic/ ecological structure variables, such as social class, residential stability, ethnic diversity, and housing structure that can be directly mapped onto each neighborhood. This means that we do not know how the mean/variance typology of cooperation norms relates to the demographic/ecological structure of the neighbourhoods. Our models did include the Index of Multiple Deprivation measured at LSOA level, although the spatial mismatch with hexagons limits its utility beyond acting as a general control for broader structural inequalities. Future studies should address this deficit with a more robust set of ecological measures.

Finally, the observational nature of the study means that we cannot engage in causal inference, only descriptive inference. Future studies should try to embed an experimental protocol into a one-wave or two-wave study, building on the one presented in this paper.

\section{Adding to the Methodological Toolbox of Criminologists}

We conclude with some thoughts on the application of the mixed-effects location-scale model in criminology, especially in terms of estimating the strength of place-based norms and/or cultural frames. Modelling the mean and variance of cluster level variables represents an advance over existing studies, where the focus has typically been on mean differences between ecological units (for exceptions see Browning et al. 2016; Brunton-Smith et al. 2018). In the present study, the mixed-effects location-scale model allowed us to provide a more nuanced picture of the strength of social norms operating within each local neighborhood, distinguishing those locations where the norm to cooperate is 'in flux' because the variance is high. Recall that it was only in neighborhoods where the mean was (relatively) low and the variance was high that legitimacy played a predictive role. We could not have estimated this without using a technique like the mixed-effects, location scale model.

There are other potential applications for this method. In addition to collective effficacy (Brunton-Smith et al., 2018), assessments of within-cluster variance may also be usefully leveraged in studies of sentencing consistency, signalling the existence of another layer of important uncertainties in sentencing outcomes between judges and courts (Brunton-Smith 
et al. 2020), or in developmental studies to differentiate those individuals experiencing more uncertain developmental pathways.

The technique might be particularly relevant to concepts like legal cynicism. Sampson and Bartusch (1998) define legal cynicism as normlessness going hand-in-hand with the belief that the law is not created or enacted to advance people's own interests, but is instead a tool used by elites to maintain power and control over them (Ewick and Sibley 1998; Tyler and Huo 2002; Gau 2015; Gifford and Reisig 2019). The standard approach of modelling legal cynicism as a neighborhood-level construct is to estimate the clusterlevel mean (Sampson and Bartusch 1998; Kirk and Papachristos 2011; Desmond et al. 2016). For example, Sampson and Bartusch (1998) found that legal cynicism predicted tolerance of deviance, arguing that community contexts "shape "cognitive landscapes" (Sampson 1997) of appropriate standards and expectations of conduct.'

But if Sampson and Bartusch (1998) had also modelled the variance around the mean, they might have more precisely estimated the collective social property of the neighborhood and its potential impact on tolerance of deviance. Imagine two neighborhoods. Both have the same (relatively high) cluster-level mean level of legal cynicism, yet the first neighborhood has a relatively low variance, while the second neighborhood has a relatively high variance. It may be that in the first neighborhood, legal cynicism is a stronger social property than in the second neighborhood, because there is greater agreement-most people do not believe that the law applies to them. Legal cynicism in the first neighborhood may thus have a stronger negative effect on tolerance of deviance than otherwise identified. In essence, without taking into account cluster-level variance in addition to cluster-level means, one might under-estimate what Sampson and Bartusch $(1998,781)$ call the '...situational and contextual basis of value attenuation.'

Imagine two more neighborhoods. Both have the same (relatively low) average level of legal cynicism. The first neighborhood has a relatively low variance around the mean and the second neighborhood has a relatively high variance. It may well be that in the first neighborhood, the opposite of legal cynicism is a stronger social property, compared to the second neigborhood. Most people have internalised the idea that the law applies to them and that it should be obeyed whatever the content. They allow the law to supersede their own judgment. Collectively, the context may provide a stronger normative influence on residents on the rejection of violence as a means to achieve social goals (cf. Jackson et al. 2013a, b; Gerber and Jackson 2017; Gerber et al. 2018).

One can also think of legal cynicism '... as a [cultural] frame through which individuals interpret the functioning and usefulness of the law and its agents' (Kirk and Papachristos 2011, 1207). According to Kirk and Papachristos (2011, 1191), when a person agrees with three attitude statements— "Laws are made to be broken", "The police are not doing a good job in preventing crime in this neighborhood", and "The police are not able to maintain order on the streets and sidewalks in the neighborhood"- they are expressing a "cultural orientation in which the law and the agents of its enforcement, such as the police and courts, are viewed as illegitimate, unresponsive, and ill equipped to ensure public safety.' This cultural frame is shaped by adaptation to neighborhood structural conditions but it is also embedded in communication and social interaction between actors in a given locality. Kirk and Papachritos (2011, 1202-1203) argue that legal cynicism is usefully represented at the neighborhood level as something that 'constrains choices for resolving grievances and protecting oneself because individuals are more likely to presume that the law is unavailable or unresponsive to their needs. In the face of such constraints, individuals may choose to engage in their own brand of social control because they cannot rely upon the law to assist them.' 
The mixed-effects, location-scale model could be used to more completely estimate the strength of shared cultural frames within a given neighborhood-again, the idea is that social consensus is strong when variance is low, so if legal cynicism thus defined has a high mean and low variance in certain neighborhoods, then we can infer that the cultural frame is particularly strong and estimate whether potential outcomes are even more powerful in such localities.

\section{Final Words}

In short, both the method and the findings presented in this paper appear worthy of more attention in the future. Public cooperation with the police is fundamental to the functioning of the justice system at every level, and the over-arching substantive message is that people's relationships with police (which we have modelled as the extent of people's willingness to cooperate with the police) cannot be considered in isolation from their relationships with each other, which we have modelled as neighborhood norms. The individual-level focus that is dominant within most procedural justice theory research, and indeed the wider body of work on public attitudes toward police, needs therefore to be complemented by a focus on group norms and values, and how these interact with people's beliefs and attitudes in generating people's willingness to cooperate and actual cooperation with police, and techniques like the mixed-effects, location-scale model will help researchers study such phenomena.

Funding The funding was provided by West Midlands Police.

Open Access This article is licensed under a Creative Commons Attribution 4.0 International License, which permits use, sharing, adaptation, distribution and reproduction in any medium or format, as long as you give appropriate credit to the original author(s) and the source, provide a link to the Creative Commons licence, and indicate if changes were made. The images or other third party material in this article are included in the article's Creative Commons licence, unless indicated otherwise in a credit line to the material. If material is not included in the article's Creative Commons licence and your intended use is not permitted by statutory regulation or exceeds the permitted use, you will need to obtain permission directly from the copyright holder. To view a copy of this licence, visit http://creativecommons.org/licenses/by/4.0/.

\section{References}

Anderson E (1990) Streetwise: race, class, and change in an urban community. University of Chicago Press, Chicago

Anderson E (1999) Code of the street: decency, violence, and the moral life of the inner city. W.W. Norton, New York

Antrobus E, Bradford B, Murphy K, Sargeant E (2015) Community norms, procedural justice and the public's perceptions of police legitimacy. J Contemp Crim Justice 31(2):151-170

Berg MT, Slocum LA, Loeber R (2013) Illegal behavior, neighborhood context, and police reporting by victims of violence. J Res Crime Delinq 50(1):75-103

Boateng FD (2017) Police legitimacy in Africa: a multilevel multinational analysis. Polic Soc 28:1-16

Bolger PC, Walters GD (2019) The relationship between police procedural justice, police legitimacy, and people's willingness to cooperate with law enforcement: a meta-analysis. J Crim Justice 60:93-99

Bottoms A, Tankebe J (2012) Beyond procedural justice: a dialogic approach to legitimacy in criminal justice. J Crim Law Criminol 102:119-170 
Bradford B, Murphy K, Jackson J (2014a) Officers as mirrors: policing, procedural justice and the (re) production of social identity. Br J Criminol 54(4):527-550

Bradford B, Huq A, Jackson J, Roberts B (2014b) What price fairness when security is at stake? Police legitimacy in South Africa. Regul Gov 8:246-268

Bradford B, Jackson J, Hough M (2014c) Police legitimacy in action: Lessons for theory and practice. In: Reisig M, Kane R (eds) The Oxford handbook of police and policing. Oxford University Press, Oxford, pp 551-570

Brennan G, Eriksson L, Goodin RE, Southwood N (2013) Explaining norms. Oxford University Press, Oxford

Browning CR, Dirlam J, Boettner B (2016) From heterogeneity to concentration: latino immigrant neighborhoods and collective efficacy perceptions in Los Angeles and Chicago. Soc Forces 95:779-807

Brunton-Smith I, Jackson J, Sutherland A (2014) Bridging structure and perception. Br J Criminol 54(4):503-526

Brunton-Smith I, Sturgis P, Leckie G (2018) How collective is collective efficacy? The importance of consensus in judgments about community cohesion and willingness to intervene. Criminology 56(3):608-637

Brunton-Smith I, Sanchez JP, Li G (2020) Re-assessing the consistency of sentencing decisions in cases of Assault: allowing for within court inconsistencies. Br J Criminol. https://doi.org/10.1093/bjc/azaa030

Carr PJ, Napolitano L, Keating J (2007) We never call the cops and here is why: a qualitative examination of legal cynicism in three Philadelphia neighborhoods. Criminology 45(2):445-480

Charlton CMJ, Michaelides DT, Parker RMA, Cameron B, Szmaragd C, Yang HY, Browne WJ (2013) StatJR Version 1.0. Southampton, U.K.: Centre for Multilevel Modelling, University of Bristol and Electronics and Computer Science, University of Southampton

Desmond D, Papachristos A, Kirk D (2016) Police violence and citizen crime reporting in the black community. Am Sociol Rev 81(5):857-876

Dirikx A, Van den Bulck J (2013) Media use and the process-based model for police cooperation: an integrative approach towards explaining adolescents' intentions to cooperate with the police. Br J Criminol 54(2):344-365

Ewick P, Silbey SS (1998) The common place of law: Stories from everyday life. University of Chicago Press

Gau JM (2015) Procedural justice, police legitimacy, and legal cynicism: a test for mediation effects. Police Pract Res 16(5):402-415

Gau JM, Corsaro N, Stewart EA, Brunson RK (2012) Examining macro-level impacts on procedural justice and police legitimacy. J Crim Justice 40(4):333-343

Gerber M, Jackson J (2017) Justifying violence: legitimacy, ideology and public support for police use of force. Psychol Crime Law 23(1):79-95

Gerber MM, Gonzalez R, Carvacho H, Jimenez-Moya G, Moray C, Jackson J (2018) On the justification of intergroup violence: the roles of procedural justice, police legitimacy and group identity in attitudes towards violence among indigenous people. Psychol Violence 8(3):379-389

Gifford FE, Reisig MD (2019). A multidimensional model of legal cynicism. Law Hum Behav 43(4):383

Goudriaan H, Wittebrood K, Nieuwbeerta P (2006) Neighborhood characteristics and reporting crime: effects of social cohesion, confidence in police effectiveness and socio-economic disadvantage. $\mathrm{Br} \mathrm{J}$ Criminol 46(4):719-742

Groff ER, Ratcliffe JH, Haberman CP, Sorg ET, Joyce NM, Taylor RB (2015) Does what police do at hot spots matter? The Philadelphia policing tactics experiment. Criminology 53(1):23-53

Hamm JA, Trinkner R, Carr JD (2017) Fair process, trust, and cooperation: moving toward an integrated framework of police legitimacy. Crim Justice Behav 0093854817710058

Hawdon J (2008) Legitimacy, trust, social capital, and policing styles: a theoretical statement. Police Q 11:182-201. https://doi.org/10.1177/1098611107311852

Hedeker D, Mermelstein RJ, Demirtas H (2008) An application of a mixed-effects location scale model for analysis of ecological momentary assessment (EMA) data. Biometrics 64:627-634

Hipp JR (2007) Block, tract, and levels of aggregation: neighborhood structure and crime and disorder as a case in point. Am Sociol Rev 72(5):659-680

Hipp JR, Faris RW, Boessen A (2012) Measuring "neighborhood": constructing network neighborhoods. Social Netw 34(1):128-140

Hipp JR, Corcoran J, Wickes R, Li T (2014) Examining the social porosity of environmental features on neighborhood sociability and attachment. PLoS ONE 9(1):xxx

Hipp JR, Williams S, Boessen A (2018) Disagreement in assessing neighboring and collective efficacy: the role of social distance. Socius 4:1-16 
Huq AZ, Tyler TR, Schulhofer SJ (2011) Mechanisms for eliciting cooperation in counterterrorism policing: a study of British Muslims. J Empir Legal Stud 8:728-761

Huq A, Jackson J, Trinkner R (2017) Legitimating practices: revisiting the predicates of police legitimacy. Br J Criminol 57(5):1101-1122

Ilan J (2018) Scumbags! An ethnography of the interactions between street-based youth and police officers. Polic Soc 28(6):684-696

Jackson J (2018) Norms, normativity, and the legitimacy of justice institutions: international perspectives. Annu Rev Law Social Sci 14:145-165

Jackson J, Bradford B (2019) Blurring the distinction between empirical and normative legitimacy? A methodological commentary on "Police legitimacy and citizen cooperation in china". Asian J Criminol 14(4):265-289

Jackson J, Gau JM (2015) Carving up concepts? Differentiating between trust and legitimacy in public attitudes towards legal authority. In: Shockley E, Neal TMS, PytlikZillig LM, Bornstein BH (eds) Interdisciplinary perspectives on trust: towards theoretical and methodological integration. Springer, New York

Jackson J, Bradford B, Hough M, Myhill A, Quinton P, Tyler TR (2012) Why do people comply with the law? Legitimacy and the influence of legal institutions. Br J Criminol 52:1051-1071

Jackson J, Bradford B, Stanko B, Hohl K (2013a) Just Authority? Trust in the police in England and Wales. Routledge, London

Jackson J, Huq A, Bradford B, Tyler TR (2013b) Monopolizing force? Police legitimacy and public attitudes towards the acceptability of violence. Psychol Publ Policy Law 19(4):479-497

Kirk D, Papachristos A (2011) Cultural mechanisms and the persistence of violence. Am J Sociol 116(4):1190-1233

Kochel TR (2018a) Police legitimacy and resident cooperation in crime hotspots: effects of victimisation risk and collective efficacy. Polic Soc 28(3):251-270

Kochel TR (2018b) Applying police legitimacy, cooperation, and collective security hypotheses to explain collective efficacy and violence across neighborhoods. Int J Comp Appl Crim Justice 42(4):253-272

Leckie G, French R, Charlton C, Browne WJ (2014) Modeling heterogeneous variance-covariance components in two-level models. J Educ Behav Stat 39:307-332

Madon NS, Murphy K, Cherney A (2016) Promoting community collaboration in counterterrorism: do social identities and perceptions of legitimacy mediate reactions to procedural justice policing? $\mathrm{Br}$ J Criminol 57(5):1144-1164

Martin JT (2018) Police and policing. Annu Rev Anthropol 47:133-148

Mazerolle L, Antrobus E, Bennett S, Tyler TR (2013) Shaping citizen perceptions of police legitimacy: a randomized field trial of procedural justice. Criminology 51:33-63

Murphy K, Sargeant E, Cherney A (2015) The importance of procedural justice and police performance in shaping intentions to cooperate with the police: Does social identity matter? Eur J Criminol 12(6):719-738

Murphy K, Madon NS, Cherney A (2017) Promoting Muslims' cooperation with police in counter-terrorism: the interaction between procedural justice, police legitimacy and law legitimacy. Polic Int J 40(3):544-559

Papachristos AV, Smith CM, Scherer ML, Fugiero MA (2011) More coffee, less crime? The relationship between gentrification and neighborhood crime rates in Chicago, 1991 to 2005. City Commun 10(3):215-240

Posch K, Jackson J, Bradford B, MacQueen S (forthcoming).'Truly free consent”? Clarifying the nature of police legitimacy using causal mediation analysis. J Exp Criminol

President's Task Force on 21st Century Policing (2015) Final Report of the President's Task Force on 21st Century Policing. Washington, DC: Office of Community Oriented Policing Services. http:// www.cops.usdoj.gov/pdf/taskforce/taskforce_finalreport.pdf. Accessed 8 Aug 2016

Reisig MD, Bratton J, Gertz MG (2007) The construct validity and refinement of process-based policing measures. Crim Justice Behav 34:1005-1027

Sampson A (2012) Great American City: Chicago and the enduring neighborhood effect. University of Chicago Press, Chicago

Sampson RJ (1997) Collective regulation of adolescent misbehavior: Validation results from eighty Chicago neighborhoods. J Aadolesc Res 12(2):227-244

Sampson RJ, Raudenbush SW, Earls F (1997). Neighborhoods and violent crime: a multilevel study of collective efficacy. Science, 277(5328):918-924

Sampson RJ, Bartusch DJ (1998) Legal cynicism and (subcultural?) tolerance of deviance: the neighborhood context of racial differences. Law Soc Rev 32:777-804 
Sampson RJ, Raudenbush SW, Earls F (1997) Neighborhoods and violence crime: a multilevel study of collective efficacy. Science 227:918-924

Sidebottom A, Tompson L, Thornton A, Bullock K, Tilley N, Bowers K, Johnson SD (2018) Gating alleys to reduce crime: a meta-analysis and realist synthesis. Justice Q 35(1):55-86

Slocum AL, Taylor TJ, Brick BT, Esbensen FA (2010) Neighborhood structural characteristics, individual-level attitudes, and youths' crime reporting intentions. Criminology 48(4):1063-1100

Spiegelhalter DJ, Best NG, Carlin BP, van der Linde A (2002) Bayesian measures of model complexity and fit. J R Stat Soc B 64:583-639

Stoutland S (2001) The multiple dimensions of trust in resident/police relations in Boston. J Res Crime Delinq 38(1):226-256

Sunshine J, Tyler TR (2003) The role of procedural justice and legitimacy in public support for policing. Law Soc Rev 37:513-548

Sutherland A, Brunton-Smith I, Jackson J (2013) Collective efficacy, deprivation and violence in London. Br J Criminol 53(6):1050-1074

Trinkner R (2019) Clarifying the contours of the police legitimacy measurement debate: a response to Cao and Graham. Asian J Criminol 14(4):309-335

Trinkner R, Jackson J, Tyler TR (2018) Bounded authority: expanding “appropriate" police behavior beyond procedural justice. Law Hum Behav 42(3):280-293

Tsushima M, Koichi H (2015) Public cooperation with the police in Japan: testing the legitimacy model. J Contemp Crim Justice 31(2):212-228

Tyler TR (2006a) Why people obey the law [second edition]. Yale University Press, New Haven

Tyler TR (2006b) Psychological perspectives on legitimacy and legitimation. Annu Rev Psychol 57:375-400

Tyler TR (2013) Why people cooperate: the role of social motivations. Princeton University Press, Princeton

Tyler TR, Fagan J (2008) Why do people cooperate with the police? Ohio State J Crim Law 6:231-275

Tyler TR, Huo YJ (2002) Trust in the law: encouraging public cooperation with the police and courts. New York: Russell-Sage Foundation

Tyler TR, Jackson J (2013) Future challenges in the study of legitimacy and criminal justice. In: Tankebe J, Liebling A (eds) Legitimacy and criminal justice: an international exploration. Oxford University Press, Oxford, pp 83-104

Tyler TR, Jackson J (2014) Popular legitimacy and the exercise of legal authority: motivating compliance, cooperation and engagement. Psychol Public Policy Law 20:78-95

Tyler TR, Trinkner R (2018) Why children follow rules: legal socialization and the development of legitimacy. Oxford University Press, New York

Warner BD (2007) Directly intervene or call the authorities? A study of forms of neighborhood social control within a social disorganization framework. Criminology 45(1):99-129

White MD, Mulvey P, Dario LM (2016) Arrestees' perceptions of the police: exploring procedural justice, legitimacy, and willingness to cooperate with police across offender types. Crim Justice Behav 43:343-364

Wickes R, Zahnow R, Corcoran J, Hipp JR (2019) Neighbourhood social conduits and resident social cohesion. Urban stud 56(1):226-248

Wo JC (2016) Community context of crime. Crime Delinq 62(10):1286-1312

Publisher's Note Springer Nature remains neutral with regard to jurisdictional claims in published maps and institutional affiliations.

\section{Affiliations}

\section{Jonathan Jackson ${ }^{1,2}\left(\mathbb{D} \cdot\right.$ lan Brunton-Smith ${ }^{3} \cdot$ Ben Bradford ${ }^{4}$.Thiago R. Oliveira' Krisztián Pósch ${ }^{4} \cdot$ Patrick Sturgis ${ }^{1}$}

1 Department of Methodology, LSE, Houghton Street, London WC2A 2AE, UK

2 University of Sydney Law School, Sydney, Australia

3 Department of Sociology, University of Surrey, Guildford, UK

4 Department of Security and Crime Science, UCL, London, UK 